\title{
Moses Finley e a economia antiga: interdisciplinaridade na produção de uma inovação historiográfica ${ }^{1}$
}

\author{
Miguel Palmeira ${ }^{2}$
}

Resumo: Este artigo analisa o modo pelo qual o historiador britânico Moses Finley valeu-se do diálogo com a Sociologia de Weber e da Antropologia de Polanyi para inovar o campo de estudos da economia da Antigüidade grecoromana. Procura-se demonstrar que a prática da interdisciplinaridade por Finley não é uma característica essencial e contínua de sua "obra", mas um processo que se institui e varia de acordo com as condições sociais nas quais e pelas quais ele se desenvolve.

Palavras-chave: História da Historiografia; Economia Antiga; Finley; Polanyi; Weber.

Em diversos trabalhos escritos entre as décadas de 1950 e 1970, o helenista britânico Moses I. Finley ${ }^{3}$ fez do diálogo com antropólogos e sociólogos um instrumento recorrente de análise do mundo greco-romano antigo. Consultando-se textos de apreciação da obra ou de trabalhos específicos de Finley, verifica-se que a interdisciplinaridade foi um dos aspectos que o levaram a se fazer percebido pelos pares como "inovador" da história econômica na Antigüidade greco-romana. $\mathrm{O}$ modo pelo qual o autor

Este texto é uma versão modificada do trabalho originalmente apresentado na mesa "Interdisciplinaridade nos estudos sobre a Antigüidade greco-romana" ( $2^{\circ}$ Encontro Nacional do GT de História Antiga da ANPUH - Porto Alegre, setembro de 2002). Trata-se das primeiras formulações, acrescidas de novas informações, da pesquisa que desde então desenvolvo na Universidade de São Paulo, sob orientação do prof. Francisco Murari Pires, a respeito do papel de Moses Finley nos debates travados entre as décadas de 50 e 70 do século $\mathrm{XX}$ sobre a economia da Antigüidade greco-romana.

${ }^{2}$ Doutorando em História Social na USP - Bolsista Fapesp.

${ }^{3}$ Finley nasceu em Nova York, em 1912, nomeado Moses Finkelstein. Mudou de sobrenome aos 29 anos por razòes desconhecidas. Em 1952, então professor da universidade de Rutgers havia 4 anos, foi convocado a comparecer diante de um subcomitê do Comitê de Segurança Interna do Senado dos EUA acusado de haver formado uma escola comunista no Institute of Pacific Relations, organismo de pesquisa sediado em Nova York na década de 1930. Tendo se negado a responder sobre sua filiação passada ao Partido Comunista, terminou perdendo ser posto na Universidade em 1953. Foi para a Inglaterra em 1954 e lá permaneceu até 1986, ano de sua morte. Naturalizou-se britânico em 1962. Para dados biográficos de Finley, ver Whittaker (1997). 
dialogou o com sociólogo alemão Max Weber (1864-1920) e com o antropólogo húngaro Karl Polanyi $(1886-1964)^{4}$ na elaboração de um modelo de "economia antiga" soou aos comentadores de Finley especialmente significativo, o traço de interdisciplinaridade que não se pode relegar ao silêncio nas apreciações do autor e de sua obra ${ }^{5}$.

Tal diálogo volta à tona neste artigo, não simplesmente para corroborar a constatação de uma filiação científica ou entrar no jogo de adicionar e subtrair anéis a uma cadeia teórica Weber-Polanyi-Finley tida por existente e por digna de nota, mas para compreender de que modo os elementos "weberianos" e "polanyianos" de que se apropriou Finley o levaram a ser percebido no universo social dos historiadores do mundo clássico como responsável pela reorganização dos estudos sobre a economia greco-romana antiga (independentemente do juízo que se faça do legado de Finley, a existência desse legado jamais lhe foi negada: a partir da década de 1970, qualquer um que pretendesse dizer algo da economia antiga e se fazer ouvir a respeito foi obrigado a posicionar-se em relação às idéias de Finley ou de pesquisadores por ele influenciados ${ }^{6}$ ). Procurar-se-á dar ênfase aqui aos acordos e desacordos de procedimentos metodológicos entre Finley e os dois autores de modo a revelar aspectos nem sempre observados das leituras de Weber e de Polanyi pelo helenista.

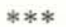

Em fins do século XIX, estudiosos da Antigüidade greco-romana disputaram a qualificação da economia dos antigos como "primitiva", porque restrita à unidade doméstica e com baixo nivel de trocas, ou como "moderna", posto que organizada com um sistema de transporte desenvolvido e caracterizada por trocas intensivas de mercadoria (Will, 1954). Embora não haja acordo entre os autores que se dedicaram a revisar os debates acadêmicos sobre a economia antiga quanto a suas origens precisas, aceita-se normalmente que foi no meio acadêmico alemão que as

\footnotetext{
${ }^{4}$ Polanyi era jurista de formação e jamais realizou trabalho de campo. Não é exato associá-lo a uma disciplina especifica, mas nas últimas duas décadas de sua vida, produziu textos, travou debates e formou discipulos no terreno da Antropologia.

5 A contribuição da Sociologia de Weber e da Antropologia de Polanyi foi destacada por Hindess (1975); Frederiksen (1975); Shaw e Saller (1981). A relação entre Finley e Polanyi mereceu comentários de Humphreys (1978); Di Donato (1991); Servet et alli (1994); a influência de Weber foi destacada por Nippel (1991); Bruhns (1998) e Morris (1999).

${ }^{6}$ Para o acordo quanto à inflexão provocada pelos trabalhos de Finley, cf. os balanços da produção sobre a economia antiga de Vegetti (1977), Hopkins (1983) e Andreau (1995).
} 
discussões primeiro adquiriram visibilidade e que dois personagens tiveram nelas papel central: o economista Karl Bücher, que sustentava a tese "primitiva", e o historiador Eduard Meyer, que contra-argumentou em favor da tese "moderna". Nas primeiras décadas do século XX, autores diversos afastaram-se dos pólos contraditórios da discussão. Cada juízo sobre a economia dos antigos tendeu, entretanto, a ser percebido como corolário da controvérsia Bücher-Meyer. A partir do final da década de 1920, "primitivistas" tornou-se termo corrente para designar opiniões associadas ao primeiro e "modernistas", ao segundo. A classificação se estendeu a quem quer que fosse tomado por participante do debate, embora nunca como autodesignação. Ao longo do século XX, a menção a esta dicotomia em regra, para negar sua pertinência, mas paradoxalmente recriando sua existência por meio do reconhecimento de duas partes de um debate nas quais ninguém dizia se enquadrar - tornou-se obrigatória a quem quer que pretendesse falar a respeito do caráter da vida econômica dos antigos, sob penas de, não o fazendo, deixar de se perceber e ser percebido como participante de um debate "secular"?

Economias "primitivas" e "modernas" constituíram problemas de pesquisa fora do âmbito dos estudos clássicos. Nas décadas que se seguiram ao fim da $2^{\mathrm{a}}$ Guerra Mundial, a história econômica chegou ao auge de seu prestígio nos principais centros de produção historiográfica. Tratava-se de uma história quantificada, quer fosse em sua vertente "serial" dos historiadores-economistas franceses ou em sua modalidade "econométrica" dos economistas-historiadores norte-americanos. Ainda nesse período, a difusão dos Grundrisse de Marx e o influxo das idéias de Karl Polanyi contribuíram para que a especificidade das sociedades pré-capitalistas fosse alvo de um renovado interesse por antropólogos como Maurice Godelier e Claude Meillassoux ${ }^{8}$.

Entre 1947 e 1953, pesquisadores procedentes de diversas áreas do conhecimento nas Ciências Sociais engajaram-se em um projeto coletivo de pesquisa sobre "aspectos institucionais do crescimento econômico" na Universidade de Columbia. Autores como Karl Polanyi, Conrad Arensberg e Harry Pearson batiam-se contra os antropólogos da economia a que

\footnotetext{
${ }^{7}$ Assim, em seu texto sobre relações agrárias na Antigüidade, Weber mencionou a controvérsia entre Bücher e Meyer sem proclamar-se favorável a nenhuma das posições ou propor solução de qualquer espécie, e seu nome figurou nas genealogias dos debates apenas muito mais tarde, quando Finley, já historiador consagrado, passaou a enaltecer a contribuição do sociólogo alemão para seus trabalhos. Sobre a história da recepção de Weber, ver Bruhns (1998).

${ }^{8}$ Cf. Cardoso e Brignoli (1983: 29-39); e Cardoso (1994: 179-180).
} 
chamavam "formalistas", que em seus estudos dos povos "primitivos" valiam-se como instrumento de análise da terminologia "formal" da Ciência Econômica. Polanyi e seu grupo procuraram demonstrar que a concepção da economia como sede de fenômenos como a parcimônia, a obtenção de excedentes pelo mercado, a formação dos preços provinha do Ocidente do século XVIII e era judiciosa no caso de disposições institucionais de um sistema de mercado. Neste caso, historicamente situado, tais disposições satisfaziam grosso modo as hipóteses fixadas pelos postulados da Economia. Durante a maior parte da história das sociedades humanas, no entanto, não se verificava nenhuma relação necessária entre a ação de economizar meios e as economias no domínio da empiria. Era portanto preciso desfazer-se da concepção enraizada da economia como um campo de experiências do qual os seres humanos foram via de regra conscientes, pois até o advento do sistema de mercado os fatos econômicos estiveram imersos em situações que não eram necessariamente de natureza econômica. No lugar do entendimento de toda economia humana como um mecanismo potencial de oferta e demanda de preços, Polanyi propunha uma análise da economia como processo social. Da significação formal de economia como "economia dos meios", passar-se-ia então à de "economia substantiva", isto é, o "processo institucionalizado de interação entre o homem e seu meio que resulta na provisão contínua dos meios materiais de satisfação das necessidades". A localização deste processo e o exame de sua ação apenas se realizaria deslocando-se a acentuação analítica de um tipo de ação racional para a configuração dos movimentos de bens e de pessoas que constituem a realidade da economia ${ }^{9}$.

Finley tomou parte nas discussões, seminários e conferências que resultaram na principal publicação coletiva "substantivista" (Trade and Market in Early Empires). Chegou a elaborar um texto para esse livro, tratando das visões de Aristóteles sobre a troca, mas por discordâncias com Polanyi e por inconveniências decorrentes de seu exílio na Inglaterra a partir 1954, terminou por não publicá-lo. O impacto das teses polanyianas sobre a interpretação de Finley da "Idade das Trevas" grega foi evidente e reconhecida pelo helenista em um de seus primeiros livros, $O$ Mundo de Ulisses $^{\prime 0}$. Uma vez que o estudo de Finley sobre a sociedade homérica não

\footnotetext{
"Cf. Polanyi, Arensberg e Pearson, "The Place of Economies in Societies", em Polanyi (1971: 116-120); e Polanyi (1971: 139-148; citação p. 145).

${ }^{10}$ Finley caracterizou a sociedade homérica como estruturada pela reciprocidade baseada na troca de presentes. "Reciprocidade" era uma das categorias da tipologia de Polanyi das "formas de integração" econômicas. Cf. Finley (2002; Polanyi é incluido nos agradecimentos: p. XXI;
} 
estava originalmente referido à polêmica entre "primitivistas" e "modernistas", restringem-se neste artigo apreciações da posição de Finley quan to ao substantivismo em $A$ Economia Antiga (doravante $E A$ ), livro que sintetiza trabalhos do autor centrados na análise dos períodos "clássicos" da história greco-romana.

A hipótese de que a economia - na acepção que lhe conferiam os economistas modernos (e corroborada por um certo senso comum) de um conglomerado de mercados interdependentes - jamais emergiu como categoria na Antigüidade greco-romana foi o ponto de partida do modelo explicativo da vida econômica antiga proposto em EA. Os antigos, segundo Fịnley, não dispunham dos elementos conceituais que juntos constituem o que hoje se designa como "economia": termos como "trabalho", "produção", "capital", "investimento", e atividades como o cultivo, o comércio, a cobrança de impostos, etc. jamais foram reconhecidos como campo específico de experiências sociais. A idéia tão cara a Polanyi de uma economia não autonomizada em relação a outros domínios da vida social serviu para Finley detectar naquilo que os modernistas viam com certo espanto um lapso intelectual dos antigos (isto é, a ausência entre estes de um pensamento econômico à altura do que realizaram em outros domínios de reflexão) um comportamento institucional específico, uma conseqüência da estrutura da sociedade antiga. A economia greco-romana era socialmente institucionalizada de modo a não ser percebida e organizada pelos antigos como esfera autônoma da vida social. Para fins analíticos, era necessário "procurar diferentes conceitos e diferentes modelos, apropriados à economia antiga, e não (ou não necessariamente) à nossa" "!. Tratava-se de descrever e explicar o funcionamento de uma economia do modo que ela se apresentava empiricamente, como queria Polanyi, opondo-se à postura, adotada por abordagens "modernizantes", de que os instrumentos analíticos que a Ciência Econômica elaborara em função de economias de mercado se ajustariam sem dificuldades uma interpretação do mundo antigo. $\mathrm{O}$ acordo quanto ao princípio de "imersão" da economia nas estruturas sociais e quanto à definição substantiva da economia e seu corolário - a necessidade de se descrever as atividades econômicas a partir de seus contextos sociais concretos, assim restituindo origem e sentidos reais a tais atividades, evitando associá-las aos padrões lógico-formais a que era afeita a Ciência

cf. ainda Shaw e Saller (1981: xix).). As discordâncias se refletem em Finley (1970) e foram posteriormente sistematizadas por Di Donato (1991).

${ }^{11}$ Finley (1992:17-34; citação p. 27). 
Econômica - serviu a comentadores de Finley e Polanyi para reconhecer nos trabalhos do primeiro a influência do segundo.

A importância da sociologia de Max Weber para a obra de Finley foi ressaltada por diversos comentadores e com relação a aspectos variados (a idéia de cidade antiga, a utilização das categorias "status" e "ordem", o recurso ao comparatismo, etc.). Em tais comentários, procurou-se de modo geral verificar se o helenista interpretou de modo tido por correto as proposições do sociólogo ou opor à suposta filiação weberiana de Finley as concepções marxistas de "classe", "exploração" e "economia". Neste texto, são examinados outros traços da contribuição de Weber, referentes menos ao que se entende normalmente ser a teoria weberiana do mundo social do que a aspectos de sua obra por ele designados como métodológicos.

Qualquer análise cientifica da vida cultural revestia-se para Weber de um caráter parcial, não apenas em decorrência da complexidade da realidade investigada exceder via de regra a capacidade de apreensão mental do pesquisador, mas porque a este cabe uma atribuição de sentido ao objeto selecionado. Não havia para esse autor a possibilidade de se empreender uma análise científica puramente objetiva dos fenômenos sociais, que fosse independente de determinadas perspectivas especiais e parciais, pois nelas estaria radicado necessariamente o princípio organizador da construção de um objeto de pesquisa. Entendendo que tal principio opera independentemente da vontade do pesquisador, Weber considerava que essa estruturação mental da realidade tanto mais conviria à ciência social quanto controlada fosse pelo pesquisador. Estabeleceu assim o "tipo ideal" como artificio de método, uma construção mental obtida mediante "a acentuação unilateral de um ou vários pontos de vista", mediante "o encadeamento de grande quantidade de fenômenos isoladamente dados, difusos e discretos, que se podem dar em maior ou menor número ou mesmo faltar por completo" ordenados segundo os pontos de vista unilateralmente acentuados, a fim de se formar um quadro homogêneo de pensamento". O "tipo ideal", recomendava Weber, deveria ser tomado não por finalidade do conhecimento, mas por um meio de aferição da proximidade ou do afastamento entre a realidade e o quadro teórico ${ }^{12}$. A construção de tipos ideais orientados para a produção de conhecimento científico passava pelo exercício da compreensão da ação social e, em seguida, pela imputação causal do curso dessa ação e de suas conseqüências. Para Weber, justificase falar em ação quando o indivíduo que age vincula um significado

${ }^{12}$ Weber (1982; citação p. 106). 
subjetivo a seu comportamento; e uma ação é caracteristicamente social na medida em que seu significado subjetivo leva em conta o comportamento de outros atores e em que o curso da ação é orientado por isso. A sociologia compreensiva busca, portanto, o sentido conferido por um ator a uma ação na medida em que tal sentido orienta a ação e produz efeitos no seu desenrolar (Weber, 1978: 4).

Quando Finley produziu seus trabalhos sobre a "economia antiga", alguns estudiosos do mundo antigo, embalados na onda quantitativista dos historiadores das épocas moderna e contemporânea, tentaram produzir estatísticas sobre Grécia e Roma ou lamentaram a falta de números confiáveis para fazê-lo. Uma história econômica da Antigüidade que tentasse tomar por base séries estatísticas depararia, segundo Finley, com dificuldades de duas ordens: 1) técnicas, pois não há uma base documental confiável para tanto; e 2) substantivas, pois certos aspectos do comportamento econômico dos antigos que não se prestavam à quantificação demandavam outros métodos de se organizar os dados disponíveis que não os dos cliométricos ou dos serialistas (Finley, 1985: 27 31; 1992: 23-26). Dentro desse quadro, o autor articulou na construção de sua visão da economia antiga dois procedimentos: de um lado, contra a idéia de que uma aproximação da realidade social de gregos e romanos darse-ia através da "evocação contínua de 'fatos' individuais", estabeleceu-se como meta a construção de modelos (ou de tipo ideais weberianos, nas próprias palavras do autor de $E A$ ). A virtude heurística desses modelos estaria em, ao apresentar uma "estruturação simplificada da realidade", obscurecer detalhes insignificantes e tornar aparentes os aspectos fundamentais da realidade investigada (Finley 1992: 182). De outro lado, estando a construção desses modelos subordinada a um exame de fontes quase sempre literárias, Finley apostava, à maneira "compreensiva" de Weber, que as percepções dos antigos a respeito de suas atividades econômicas tinham conseqüências objetivas para o desenvolvimento dessas atividades.

Um exemplo de como essa prerrogativa metodológica "compreensiva" encontra-se no capítulo 2 de $E A$, no qual Finley busca traçar aspectos do padrão de escolhas econômicas inscrito na "estrutura cultural psicológica" e na "unidade política singular" que, segundo ele, constituiam mundo antigo greco-romano, bem como fornecer os instrumentos de análise mais adequados à sua abordagem. Examinando os significados (para os antigos) das atividades econômicas e as condições sociais nas quais estes se constituíam, afirma que entre gregos e romanos, 
especialmente aqueles que ocupavam a parte alta da escala social, o padrão do dispêndio de bens e de energias e o modo social de aquisição de riquezas ligava-se à posição de um indivíduo ou grupo no espectro de status sociais, e não a qualquer sorte de racionalização econômica (o status social elevado envolvia gasto competitivo e ostentatório, ao passo que a aquisição vulgar era relegada aos individuos das classes baixas que, se bem-sucedidos economicamente, incorporavam rapidamente a cultura de consumo conspícuo) ou pertencimento a um lugar determinado na estrutura das relações sociais de produção, isto é, a uma "classe". Finley tentava ocuparse assim das questões com que efetivamente depararam os antigos, a um só tempo descartando argumentações construidas a partir de casos isolados, inferências fundadas em padrões de comportamento estranhos à experiência dos agentes sociais (como a identificação de "classes") e indo além dos aspectos a respeito dos quais estes agentes expressavam alguma sorte de consciência formal (como a pertença a ordens).

Nem para Polanyi nem para Weber Finley bateu continência como um historiador que traduz em casos concretos as teorias gerais de sociólogos e antropólogos, mesmo que, em momentos específicos, tenha expressado sua divida intelectual em relação a ambos os autores. Em um movimento significativo de diferenciação de suas matrizes, discutiu com as obras de Weber e Polanyi e delas discordou, mais do que em um ou outro aspecto meramente pontual, levando às últimas conseqüências as proposições de método por eles avançadas. Quanto ao estatuto do pensamento "econômico" em Aristóteles, que Polanyi considerava não apenas brilhante mas "um testemunho contemporâneo de alguns dos primeiros traços de trocas de mercado incipientes em sua primeira aparição na história da civilização" (Polanyi, 1971: 81), Finley, como que fiel à tradição polanyiana de descrição das economias tal qual elas se apresentam empiricamente, observando como elas estão institucionalizadas, examinou os textos aristotélicos em que se baseara Polanyi e concluiu que na Ética Nicômaquéia, "ao invés de uma análise econômica pobre ou insuficiente, é mais correto dizer que não há qualquer análise econômica” (Finley, 1970: 15), da qual tampouco encontram-se sinais na Politica (Finley, 1970: 18) não por falta de perspicácia de Aristóteles, mas porque "análise econômica" não constava da suas preocupações. Em relação a Weber, para mencionar uma dissonância somente no campo da economia antiga, a crença do sociólogo alemão na "ineficiência" do trabalho escravo foi desqualificada por meio do expediente weberiano de se levar em conta o sentido atribuído pelos atores sociais a sua ações (o que não significa formular o problema 
nos mesmos termos): nem a eficiência nem a produtividade, dizia Finley, eram fatores operantes nas ações dos proprietários de escravos da Antigüidade, não servindo, portanto, para explicar o funcionamento da escravidão. As leituras de Weber e de Polanyi têm, portanto, implicações decisivas para a produção finleyniana, mas também na qualidade de leituras não-doutrinais, em que não há pudores de se jogar Weber contra Weber ou Polanyi contra Polanyi.

Uma vez que, no campo da economia antiga, a necessidade da inovação e os sentidos que lhe atribuíram os historiadores envolvidos nos debates estiveram (e estão) em disputa, também a natureza das contribuições de Weber e de Polanyi são controversas para os autores dos comentários a respeito de Finley. A quem procurar por sinais inequívocos de weberianismo e/ou polanyianismo, os testemunhos dados por Finley sobre seus supostos mestres soarão ambíguos. Weber, a respeito de quem dizia Finley ter seu próprio trabalho provocado "mais do que qualquer outro nas recentes décadas a discussão (...) entre historiadores da Antigüidade...”, que o helenista admirava por "sua análise da economia e da estrutura social antigas (...) sem paralelos", é duramente criticado no mesmo texto em que tecidas estas loas por sua concepção da estrutura política ateniense como forma típica de dominação carismática ${ }^{12}$. Polanyi, o autor criticado em 1970 por sua visão anacrônica de análise econômica, é descartado em 1972 para os propósitos de pesquisa de Finley em razão de ignorar a importância do comércio para os mercados camponeses para o mundo antigo e por apresentar "modelos primitivos... inúteis" (Finley, 1975: 117). Os movimentos cumpridos por Finley de aproximação e de afastamento em relação aos predecessores se desenrolam também na sutileza dos agradecimento rituais de prefácio (cf. nota 9 acima) e das notas de pé-depágina. Em duas das ocasiões que Finley manifestou-se sobre Polanyi - no primeiro capítulo de $E A$ (original de 1973) e na publicação (em 1975) de uma conferência de 1972 intitulada "A Antropologia e os Clássicos" - citou um artigo da antropóloga Sally Humphreys como fonte de avaliação e crítica da obra de Polanyi. Publicado em 1969 no periódico History and Theory, o texto menciona Finley como transmissor, ao lado do assiriólogo A. L. Oppenheimer, das idéias de Polanyi aos historiadores de História Antiga (Humphreys, 1978: 42-43). Humphreys reeditou-o como capitulo de uma coletânea de artigos em 1978. A posição de Finley nas discussões sobre a economia antiga deixara então de ser marginal, e uma das críticas

${ }^{12}$ Ver Finley, 1985 (pp. 88 e 90 para a citação) 
comuns a seu modelo explicativo passou a ser a dependência de uma concepção polanyiana de economia (cf. Hindess, 1975; Favory, 1981). O artigo de Humphreys foi suprimido das notas de pé-de-página dos textos de Finley que a citavam, quando estes foram reeditados em $1985^{13}$.

Por bem estruturadas que sejam, com suas regras de funcionamento e enraizamento institucional próprios, as disciplinas acadêmicas jamais são sistemas absolutamente fechados, impermeáveis a influências de outras disciplinas. Em certo sentido, portanto, a interdisciplinaridade está por toda parte e ajuda a conformar desenvolvimento das práticas cientificas, assim desejem ou não aqueles engajados nessas práticas. Podemos imaginar em oposição a essa modalidade "frouxa" de interdisciplinaridade aquela em que se dá uma importação consciente para uma determinada disciplina de modelos, problemáticas, conceitos e métodos primeiro formalizados em disciplinas "estrangeiras" ${ }^{4}$. A essa segunda modalidade aludem os historiadores e cientistas sociais quando fazem do uso da "interdisciplinaridade" motivo de pregação por uma aliança entre disciplinas e seus respectivos profissionais. Pensadas as disciplinas como "sistemas", ou, como sugere Bernard Lepetit (1999), como "culturas", e as trocas disciplinares como "processos de aculturação", devemos admitir, em primeiro lugar, que a importação de modelos teóricos não se dá de forma independente das configurações específicas da cultura que exporta e da cultura que importa os modelos; em segundo lugar, que, havendo regras de funcionamento próprias a cada disciplina que implicam maneiras especificas de perceber e classificar as sociedades humanas, todo e qualquer ato interdisciplinar envolve um esforço de tradução para sua própria cultura de uma cultura estrangeira e, portanto, uma traição, ainda que parcial, das características originais do modelo adotado.

Se toda transferência de procedimentos de uma disciplina para outra (ou de um autor para outro) implica uma traição parcial (ou mesmo

\footnotetext{
${ }^{13}$ Brent Shaw e Richard Saller, historiadores postos na condição de discípulos na edição de um dos livros de Finley, parecem ter ecoado, na introdução a Economia e Sociedade na Grécia Antiga dedicada à discussão da obra e da vida de Finley, as preocupações do helenista: "[a] influência desse grupo [de Polanyi] não deve, entretanto, ser superestimada: Polanyi claramente causou forte impressão, mas Finley foi cuidadoso em mais de uma ocasião ao sugerir a natureza sugestiva da obra de Polanyi, distanciando-se ao mesmo tempo de todas as sua conclusões formais" (Shaw e Saller, 1981: xix).

14 Adota-se, com pequenas modificações, a concepção de interdisciplinaridade de Bernard Lepetit (1999).
} 
um conjunto de incompreensões), não há motivos para ver algo de extraordinário nesse traço do uso finleyniano da interdisciplinaridade. Talvez caracterizasse Finley no universo social dos historiadores da Antigüidade, tradicionalmente auto-referido e até a primeira metade do século XX pautado teoricamente pela crítica textual de tipo filológico, o esforço consciente de incorporar pressupostos e procedimentos de sociólogos e antropólogos, ou, em uma palavra, sua modalidade controlada de traição. Essa interdisciplinaridade controlada não significou, porém, um diálogo travado sempre no mesmo tom. Finley deu a seus escritos diferentes sentidos, assim como fizeram seus comentadores, conforme variaram as condições de produção do diálogo.

Ao longo deste artigo, apresentou-se em linhas muito gerais o modo pelo qual a prática interdisciplinar foi um dos elementos da inovação finleyniana no cenário dos debates sobre história econômica da Antigüidade clássica. O recurso a Polanyi e a Weber parece apenas um dos dados pertinentes para uma resposta sobre a questão da inovação, mas não suficiente, já que Finley não se apoiou somente nesses dois autores e tampouco esgotou seu método na prática da interdisciplinaridade. Ademais, para compreender o efeito que tiveram as teses de Finley nos debates sobre a economia antiga, talvez seja preciso considerar que a idéia de que há "mérito", "pioneirismo" ou "inovação" embutido em certas construções teóricas é necessariamente ancorada em uma situação determinada de um campo de estudos e precedida de uma percepção específica do estado desse campo sustentada por alguém que ocupa uma posição dentro dele. Dizer algo de "novo" equivale assim a dizer algo que seja reconhecido enquanto tal pelos pares em um universo acadêmico preciso. A interdisciplinaridade está por toda parte; sua transformação em algo tangível e carregado de significado é um processo - no caso de Finley, pleno de variações - que não se esgota na economia argumentativa de um autor e passa pelas lutas de classificação - isto é, de divisão e de associação - dos -ismos (weberianismo, polanyianismo, marxismo, etc.), constitutivas do mundo social dos historiadores.

\section{Bibliografia}

Andreau, Jean. 1995. "Présentation". Annales HSS (dossiê economia antiga), n. 5, pp. 947-960.

Bruhns, Hinnerk. 1998. "À propos de l'histoire ancienne et de l'économie politique chez Max Weber". Introdução a M. Weber, Économie et société dans l'antiquité, Paris: La Découverte, pp. 9-59. 
Cardoso, Ciro F. 1994 (1988). "Economias e sociedades antigas. Conceitos e debates". In: Sete Olhares Sobre a Antigüidade. Brasília: UnB, pp. 17392 .

Cardoso, Ciro e Brignoli, Hector. 1983 (1976). Os Métodos da História. Rio de Janeiro: Ed. Graal.

Donatto, Ricardo di. 1991. "Tra Omero e Aristotele. Premesse per una discussione tra Finley i Polanyi". Opus, VI-VIII, 1987-1989, pp. 265-274.

Favory, François. 1981. "Validité des concepts marxistes pour une theorie des sociétés de l'Antiquité”. Klio, vol. 63, n. 2, pp. 313-330.

Finley, Moses I. 1970. "Aristotle and economic analysis". Past and Present, 40 , pp. 3-25.

. 1975 (1972). "Anthropology and the Classics". In: Use and Abuse of History. Londres, Chatto \& Windus, pp. 102-119.

. 1992 (1973; 2a edição revista: 1985). The Ancient Economy. Nova York: Penguin.

Windus.

1985. Ancient History. Evidences and Models. Londres: Chatto \&

2002 (1954). The World of Odysseus. Nova York: New York Review of Books.

Frederiksen, M. W. 1975. "Theory, evidence and the ancient economy", The Journal of Roman Studies, vol.65, pp. 164-171.

Hindess, B. 1975. "Extended review". Sociological Review, 23, pp. 678697.

Hopkins, Keith. 1983. "Introduction". In: Garnsey, P., Hopkins, K. e Whittaker, C. R. (orgs.), Trade in the Ancient Economy, Londres, Chatto \& Windus, pp. ix-xxv.

Humphreys, S. C. 1978 (1969). "The work of Karl Polanyi". In: Anthropology and the Greeks. Londres: Routledge \& Kegan Paul, pp. 31-75 (276-283, para as notas).

Lepetit, Bernard. 1999. "Propositions pour une pratique restreinte de l'interdisciplinarité". In: Carnet de Croquis. Sur la connaissance historique. Paris: Albin Michel, pp. 303-313.

Morris, I. 1999. "Foreword". In: M. I. Finley. The Ancient Economy. Berkeley e Los Angeles: University of California Press, pp. ix-xxxvi

Nippel, Wilfred. 1991. "Finley and Weber. Some comments and theses". Opus, VI-VIII, 1987-1989, pp. 43-50.

Polanyi, Karl. 1971. Primitive, Archaic, and Modern Economies. Boston: Beacon Press. 
Servet, Jean Michel, Macourant, Jérôme. \& Tiran, Andre 1998. "La réception de la pensée de Karl Polanyi”. In: Servet, J.-M., Macourant, J. \& Tiran, A. (orgs.). La Modernité de Karl Polanyi. Paris: L'Harmattan, pp. 384-398.

Shaw, B. e Saller, R. 1981. "Editor's Introduction". In: M. I. Finley, Economy and Society in Ancient Greece, pp. xxi-xxvi.

Vegetti, M. 1977. "Introduzione". In: Vegetti, M. (org.) Marxismo e società antica. Milão: Feltrinelli, pp. 11-65.

Weber, Max. 1978 (1921). "Basic Sociological Terms". In: Economy and Society. Outlines of Interpretative Sociology. (vol. 1). Berkeley e Los Angeles: University of California Press, pp. 3-62.

. 1982. "A 'objetividade' do conhecimento nas ciências sociais". In: Sociologia (coletânea organizada por Gabriel Cohn). São Paulo: Ática, pp. 79-127.

Will, Édouard. 1954. "Trois quarts de siècles de recherches sur l'économie grecque antique". Annales ESC, n. 9, pp. 7-22.

Whittaker, C. R. 1997. "Moses Finley, 1912-1986". Proceedings of the British Academy, 94, 459-472. 